Int. J. Electrochem. Sci., 11 (2016) $5807-5818$

\title{
Capacity Improvement of Tin-Deposited on Carbon-Coated Graphite Anode for Rechargeable Lithium Ion Batteries
}

\author{
In-Tae Kim ${ }^{1}$, Jaeho Lee ${ }^{1,3}$, Jung-Chun An ${ }^{2}$, Euney Jung ${ }^{4}$, Hong-Ki Lee ${ }^{5}$, Masayuki Morita ${ }^{1, *}$, \\ Joongpyo Shim, \\ ${ }^{1}$ Graduate School of Science and Engineering, Yamaguchi University, Ube, 755-8611, Japan \\ ${ }^{2}$ Research Institute of Industrial Science \& Technology, Pohang, Gyeongbuk 37673, Korea \\ ${ }^{3}$ Department of Nano \& Chemical Engneering, Kunsan National University, Jeonbuk, 54150, Korea \\ ${ }^{4}$ Ruby Co., Ltd., Wanju-gun, Jeonbuk, 55319, Korea \\ ${ }^{5}$ Fuel Cell Regional Innovation Center, Woosuk University, Jeonbuk, 55319, Korea \\ *E-mail: morita@yamaguchi-u.ac.jp, jpshim@kunsan.ac.kr
}

doi: $10.20964 / 2016.07 .15$

Received: 15 March 2016 / Accepted: 3 May 2016 / Published: 4 June 2016

Sn nanoparticles (NPs) were dispersed on carbon-coated graphite (cG) substrate by the impregnation method using $\mathrm{SnCl}_{2}$ as the precursor and $\mathrm{NaBH}_{4}$ as the reducing agent. Sucrose was carbonized to form the coating layer on graphite. The amount of the amorphous carbon-coating layer on the graphite was measured by thermogravimetric analysis. The results of scanning electron microscopy, X-ray diffraction, and inductively coupled plasma atomic emission spectroscopy confirmed the deposition of Sn NPs on the graphite substrate. Sn-deposited materials were electrochemically characterized by charge-discharge cycling. Sn-deposited graphite (Sn/G) showed higher capacity than graphite, and Sndeposited cG $(\mathrm{Sn} / \mathrm{cG})$ showed better electrochemical performance than $\mathrm{Sn} / \mathrm{G}$ in terms of capacity, coulombic efficiency and cyclability.

Keywords: Rechargeable lithium-ion batteries, Sn nanoparticles, Carbon-coated graphite

\section{$\underline{\text { FULL TEXT }}$}

(C) 2016 The Authors. Published by ESG (www.electrochemsci.org). This article is an open access article distributed under the terms and conditions of the Creative Commons Attribution license (http://creativecommons.org/licenses/by/4.0/). 